\title{
Procedures for estimation of genetic persistency indices for milk production for the South African dairy industry
}

\author{
B.E. Mostert", R.R. van der Westhuizen and H.E. Theron \\ ARC-Animal Production Institute, Private Bag X2, Irene 0062, South Africa
}

\begin{abstract}
Procedures have been developed for calculation of a Persistency Index for South African dairy breeds. This index is based on the Canadian Persistency Index, which is simple and easy to understand. Data used in this study were test-day records of the first three lactations, as included in the National Dairy Genetic Evaluations of South Africa, of the Ayrshire, Guernsey, Holstein and Jersey breeds. Interpolation, using the Wilmink curve, was done on these test-day records to calculate 60-day and 280-day yields for each cow and lactation. Variance components have been estimated for these yields to be used in breeding value estimations, using bivariate evaluations and a repeatability model. To obtain independence of persistency from total milk yield, 305-day milk yield estimated breeding values were included as covariates in the genetic model for estimation of breeding values for 60- and 280-day yields. The Persistency Index will be released for sires with progeny following each national dairy genetic evaluation, allowing the South African dairy industry to select for changes in persistency in future.
\end{abstract}

Keywords: Ayrshire, Guernsey, Holstein, Jersey, Repeatability model, test-day records

\# Corresponding author. E-mail: Bernice@arc.agric.za

\section{Introduction}

Lactation persistency can be defined as the ability of a cow to maintain a relatively constant milk yield throughout her lactation (Strabel et al., 2001), or the ability of a cow to continue producing milk at a high level after reaching the peak of her lactation (Jamrozik et al., 1998). Persistency therefore gives an indication of the flatness of the production curve and for ease of interpretation, should be independent of level of production (Jensen, 2001).

Improvement in persistency through selection allows for the possibility of using cheaper food around peak yield (Sölkner \& Fuchs, 1987) and may reduce stress due to a high peak production (Zimmerman \& Sommer, 1973). There is an advantageous relationship between flat lactation curves and a higher disease resistance. It is also often claimed that cows with a high persistency are less susceptible to nutritional disorders and, perhaps as a result of this, more fertile. This could be the result of low energy needs at the onset of lactation, causing these cows to have lower negative energy balances (NRS Handbook, 2004). Strabel et al. (2001) concluded that more persistent lactations are advantageous since they are associated with fewer health problems and reduce feeding and reproductive costs, and also result in a higher yield for longer during the lactation.

Persistency therefore has a direct economic value. Reductions of feed (replacement of concentrates by roughages (Sölkner \& Fuchs, 1987; Gengler 1995)), health and reproductive costs are the major factors favouring more persistent cows (Sölkner \& Fuchs, 1987; Dekkers et al., 1996). Gengler (1995) found that the reduction in feed costs gives persistency a relative economic weight of approximately $3 \%$ compared to yield. Dekkers et al. (1996) estimated the economic value of persistency in dairy cattle from the expected impact on feed cost and milk returns to be approximately $5 \%$ relative to the economic value of production traits. If the possible positive genetic relationship between persistency and disease resistance could be verified, the economic importance of persistency could be even higher (Jensen, 2001). According to Gengler (1995) the effect of a better persistency on health and reproductive costs would increase the relative economic weight of persistency to about $7 \%$ of the economic value of milk.

In light of the clear economic benefit that selection for persistency of milk production offers to the dairy producer, the aim of this study was to develop genetic values for persistency of milk production and to introduce these values to the South African dairy industry. 


\section{Material \& Methods}

This study was based on test-day records of the first three lactations, as included in the National Dairy Genetic Evaluations of South Africa, of the Ayrshire, Guernsey, Holstein and Jersey breeds. These datasets were therefore already edited according to the specifications of the South African National Dairy Genetic Evaluation System (Mostert et al., 2006a) and adjusted for heterogeneous variances due to days in milk and parity (Mostert et al., 2006b). From these datasets the following lactations were selected to be included in the interpolation procedure for ultimately constructing a persistency index:

- All lactations having at least three test-day records;

- All lactations longer than 275 days in milk. follows:

The persistency index was based on that used in Canada (Schaeffer et al., 2000) and was defined as

$$
E B V_{\text {persistency }}=\left(\left(\left(E B V_{280}-E B V_{60}\right)+y_{280}\right) / y_{60}\right) * 100
$$

Where:

$E B V_{60}$ and $E B V_{280}=$ breeding values for milk yield on day 60 and day 280 of lactation;

$y_{60}$ and $y_{280}=$ average milk yields on day 60 and day 280 of lactations of cows in the genetic base, which were cows born in 2000 for the Holstein and Jersey breeds and cows born in 1995 for the Ayrshire and Guernsey breeds.

The Wilmink curve (Wilmink, 1987) was used for interpolation and was therefore modelled on the test-day records of the remaining lactations in order to calculate milk yields on days 60 and 280 of lactation, for every lactation of every cow in the dataset:

Where

$$
y_{t}=\beta_{0}+\beta_{1} t+\beta_{2} \exp (-0.05 t)
$$

$$
\begin{array}{lll}
y_{t} & = & \text { milk yield on fixed day } \mathrm{t} ; \\
\beta_{0}, \beta_{1} \text { and } \beta_{2} & = & \text { coefficients of the lactation curve function. }
\end{array}
$$

Data was carefully selected for variance component estimation, using the following criteria:

- Both parents should be known;

- The cow should have a recorded first lactation;

- There should be at least five cows in a contemporary group;

- There should be daughters of at least two sires in a contemporary group;

- Sires should be presented in at least three contemporary groups.

After reaching these criteria, a random sample of $35 \%$ of the contemporary groups was selected for the Holstein evaluation. However, in order to obtain convergence, defined as standardized maximum change of the solutions from one round to the next with a stopping criterion of 0.001 , the Ayrshire and Guernsey datasets had to be less strictly selected with the only criterion applied being, that both parents should be known. Pedigrees were traced back for three generations.

Bivariate genetic evaluations were run on these selected datasets, using VCE4 (Groeneveld \& GarciaCortes, 1998) to estimate (co)variance matrices that could be used for breeding value estimation of milk

\begin{tabular}{|c|c|c|}
\hline \multicolumn{3}{|l|}{ Where } \\
\hline$y_{i j k l m n o p}$ & $=$ & milk yield on day 60 or 280 of cow i in lactation m; \\
\hline & $=$ & mean yield; \\
\hline$C G_{j m}$ & $=$ & $\begin{array}{l}\text { fixed effect of } j^{\text {th }} \text { herd } x \text { season } x \text { parity x number of times milked on the test-day } \\
\text { (contemporary group); }\end{array}$ \\
\hline$S_{k m}$ & $=$ & fixed effect of $\mathrm{k}^{\text {th }}$ calving season in lactation $\mathrm{m}$; \\
\hline$A C_{l m}$ & $=$ & fixed effect of $\mathrm{l}^{\text {th }}$ age of calving class in lactation $\mathrm{m}$; \\
\hline
\end{tabular}
yields on days 60 and 280 of lactation. A repeatability model was implemented in order to accommodate different lactations for the same cow in the dataset. The model used, was as follows:

$$
y_{i j k l m n o p}=\mu+C G_{j m}+S_{k m}+A C_{l m}+C Y_{n m}+C I_{o m}+P E_{i}+A_{i}+e_{i j k l m n o p}
$$




$\begin{array}{lll}C Y_{n m} & = & \text { fixed effect of } \mathrm{n}^{\text {th }} \text { calving year of lactation m; } \\ C I_{o m} & = & \text { fixed effect of } \mathrm{o}^{\text {th }} \text { previous calving interval class of lactation m; } \\ P E_{i} & = & \text { permanent environmental (random) effect to account for common effects of } \\ & & \text { environment associated with all test-day records of cow } \mathrm{i} ; \\ A_{i} & = & \text { animal additive genetic effect of cow i; } \\ e_{i j k l m n o p} & = & \text { random residual error. }\end{array}$

The effects included in this model were similar to those used in the South African National Dairy Genetic Evaluation System (Mostert et al., 2006a) and proved to be significant (SAS, 2003) for all traits and breeds in this study. However, the season of calving concatenated in the contemporary group, was classified into six seasons, starting with December/January, in order to make the comparison of cows within the contemporary group more refined. The season included as a fixed effect within parity was still defined as a summer (October-March) vs. winter season (April-September), as used in the South African National Dairy Genetic Evaluation System. Age classes (14) were allocated across lactations, as in the derivation of standard lactation curves by Mostert et al. (2001). Calving interval classes (9) were allocated using standard deviation units (Mostert, 2007). All these fixed effects were based on information from the nearest test-day to days 60 and 280 of lactation, respectively.

For the estimation of breeding values of milk yields at days 60 and 280 of lactation, PEST (Groeneveld \& Kovac, 1990) was run on the complete populations, using the unselected datasets. Pedigrees were, however, traced back as far as possible and genetic groups were incorporated to ensure that base animals enter the evaluation on the appropriate genetic level.

The Statistical Analysis System (SAS, 2003) was used to calculate Pearson correlation coefficients between predicted milk yields, using the Wilmink curve, and actual yields on days 60 and 280 in milk, as well as for calculation of Pearson correlation coefficients between persistency indices and 305-day lactation estimated breeding values.

\section{Results and Discussion}

Persistency can be measured in many different ways (Gengler, 1996). The major concepts are measures based on mathematical lactation curve models; measures based on ratios between total, partial, maximum or other yields and measures based on variation of yields during the lactation. Random regression models for test-day yields allow curves to be estimated for each lactation of every cow (Jamrozik et al., 1997). Therefore, a measure of persistency based on the shape of the lactation curve after peak seems to be a logical way of describing potential to maintain the level of production (Jamrozik et al., 1998). South Africa, however, uses a Fixed Regression Test-Day Model for the National Genetic Dairy Evaluations (Mostert et al., 2006a). It was therefore decided to base genetic values for persistency on the decline in production from day 60 until day 280 of lactation, as defined by Schaeffer et al. (2000). This persistency index has the advantage that it is simple and easily understood by breeders.

Table 1 Pearson correlation coefficients between actual and predicted milk yields, using interpolation based on the Wilmink curve, on days 60 and 280 of lactation, respectively, for the different breeds

\begin{tabular}{lrrrrr}
\hline Breed & Total records & \multicolumn{2}{c}{ 60-Day Milk Yield } & \multicolumn{2}{c}{ 280-Day Milk Yield } \\
& Actual & Correlation & $\begin{array}{r}\text { Actual } \\
\text { records }\end{array}$ & Correlation \\
\hline Ayrshire & 22874 & 558 & 0.962 & 940 & 0.938 \\
Guernsey & 8806 & 217 & 0.968 & 366 & 0.935 \\
Holstein & 496755 & 12832 & 0.939 & 19565 & 0.929 \\
Jersey & 191344 & 4840 & 0.942 & 7638 & 0.936 \\
\hline
\end{tabular}


The selection criteria for inclusion of reliable lactations for the interpolation procedure resulted in a pronounced decrease in the number of cows involved in this study compared to the cows included in the National Genetic Dairy Evaluations, in all breeds. For the Ayrshire breed the number of cows decreased from 58731 included in the National Genetic Dairy Evaluation, to 25959 cows (44\%), the Guernsey breed from 22847 to 11154 (49\%), the Holstein breed from 1168559 to 602346 (52\%) and the Jersey breed from 450313 to 215003 (48\%). However, to ensure reliable interpolation estimates for milk yields on days 60 and 280 of lactation, using the Wilmink curve, these selection criteria were deemed unavoidable. In Table 1 the correlation coefficients between predicted and actual milk yields on days 60 and 280 of lactation for the different breeds, are indicated.

From Table 1 it is clear that only a fraction of the data consisted of actual measurements at day 60 (less than 3\%) and day 280 (less than 5\%) of the available lactations. However, predictions of these values using interpolation based on the Wilmink curve were quite accurate, yielding Pearson Correlation coefficients of higher than $92 \%$ for all breeds and traits. Milk yield at 60 days in milk was estimated more accurately for all breeds compared to the estimates for milk yield at 280 days in milk.

In Table 2 variance component ratios \pm s.e. for 60 and 280 days in milk, are listed. Some interesting differences with regard to the variance component ratios amongst the breeds can be noted. The highest heritability was estimated for 60-day milk yield of the Guernsey breed $(0.326 \pm 0.030)$ and the lowest heritability for 280-day milk yield of the Holstein breed $(0.133 \pm 0.014)$. Heritability ratios were higher for 60-day milk yields of especially the Guernsey breed (14\% higher), as well as the Ayrshire breed (6\% higher) compared to estimates for 280-day milk yield, while those for the Holstein and Jersey breeds were rather similar. Meyer et al. (1989) published pooled heritability estimates of 22\% for 31- to 60-day milk yield and $17 \%$ for 271- to 300-day milk yield from a univariate fixed effects model. Swalve (1995) estimated heritabilities of $24 \%$ for $2^{\text {nd }}$ and $26 \%$ for $8^{\text {th }}$ first lactation milk yield tests using test-day REML models, while Druet et al. (2004) reported minimal and maximal values for heritability of milk yield over lactation of 0.16 and 0.45 , respectively, using a reduced rank test-day model. This study's estimates correspond well with this, except for the Holstein's estimates that are lower for both traits.

Table 2 Variance component ratios and correlations ( \pm s.e.) for days 60 and 280 of lactation for the different breeds

\begin{tabular}{|c|c|c|c|c|}
\hline & Ratio type & Variance $c$ & onent ratio & Correlation \\
\hline \multirow{4}{*}{ Ayrshire } & & 60-day milk yield & 280-day milk yield & \\
\hline & Residual & $0.599+0.010$ & $0.761+0.009$ & $0233+0011$ \\
\hline & Direct & $0.230 \pm 0.014$ & $0.169 \pm 0.013$ & $0.603 \pm 0.040$ \\
\hline & Permanent Environment & $0.171 \pm 0.014$ & $0.070 \pm 0.013$ & $0.809 \pm 0.077$ \\
\hline \multicolumn{5}{|l|}{ Guernsey } \\
\hline & Residual & $0.415 \pm 0.017$ & $0.653 \pm 0.014$ & $0.256 \pm 0.022$ \\
\hline & Direct & $0.326 \pm 0.030$ & $0.184 \pm 0.025$ & $0.883 \pm 0.037$ \\
\hline & Permanent Environment & $0.259 \pm 0.029$ & $0.163 \pm 0.023$ & $0.681 \pm 0.059$ \\
\hline \multicolumn{5}{|l|}{ Holstein } \\
\hline & Residual & $0.497 \pm 0.015$ & $0.694 \pm 0.017$ & $0.200 \pm 0.020$ \\
\hline & Direct & $0.141 \pm 0.013$ & $0.133 \pm 0.014$ & $0.782 \pm 0.034$ \\
\hline & Permanent Environment & $0.362 \pm 0.019$ & $0.173 \pm 0.021$ & $0.752 \pm 0.048$ \\
\hline \multicolumn{5}{|l|}{ Jersey } \\
\hline & Residual & $0.579 \pm 0.008$ & $0.689 \pm 0.008$ & $0.246 \pm 0.008$ \\
\hline & Direct & $0.210 \pm 0.014$ & $0.212 \pm 0.013$ & $0.802 \pm 0.019$ \\
\hline & Permanent Environment & $0.211 \pm 0.013$ & $0.099 \pm 0.011$ & $0.827 \pm 0.019$ \\
\hline
\end{tabular}

Permanent environmental variance accounted for a large proportion of the phenotypic variance, with the Holstein breed allocating the most for both traits and the Ayrshire breed the least to the permanent environment. Residual variance was highest for the Ayrshire breed for both traits, while the Guernsey and 
Holstein analyses produced much lower estimates for both traits. These results are in line with variance component ratios published by Mostert et al. (2006a) for the different breeds.

Also interesting is the difference between the correlations between 60- and 280-day milk yields among the breeds. The Ayrshire analyses estimated a much lower genetic correlation between 60 - and 280-day milk yields $(0.603 \pm 0.04)$ compared to the other breeds (all above 0.78$)$, with the Guernsey breed showing the highest genetic correlation $(0.883 \pm 0.037)$. Large variation also exists in the literature with regard to genetic correlations between milk yields at these test-days. Danell (1982) published genetic correlations of $0.52-0.55$ between first lactation milk yields at the second and $9^{\text {th }}$ tests, while Druet et al. (2004) reported a genetic correlation of 0.603 between milk yield on day 50 and day 275 in second lactation and in 2004 Gengler et al. gave an estimate of 0.78 for the genetic correlation between first lactation milk yields at days 65 and 285 of lactation.

The correlations between the permanent environmental effects of the traits are higher than those reported in the literature. For the permanent environmental effects, the lowest correlation was obtained for the Guernsey breed $(0.681 \pm 0.059)$, with the other breeds between 0.752 and 0.827 . On the other hand, Danell (1982) reported much lower correlations of 0.33 - 0.37 between first lactation milk yields at the second and $9^{\text {th }}$ tests. One should, however, keep in mind that the estimates from this study were averaged over three lactations after heterogeneity of variance due to days in milk and parity has been accounted for.

Milk yield, however, has an important influence on persistency: Total milk yield is the area below the graph of a lactation curve and yield at every moment of lactation is a function of the curve. Furthermore, an animal with a very high production at peak would likely have a steeper slope than a low producing animal (Gengler, 1990). To test Gengler's (1996) recommendation that a good persistency measure should be independent from yields, the correlation coefficient between persistency indices and 305-day milk yield estimated breeding values (EBVs) was calculated for the Jersey breed. A high estimate of -0.81 was obtained, indicating that animals with high 305-day EBVs have low persistency and vice versa. To obtain independence from total milk yield and to support the strong argument of Sölkner \& Fuchs (1987) that persistency should be estimated keeping lactation milk yield constant, 305-day milk yield EBVs were included as covariates in the genetic model for estimation of EBVs for 60- and 280-day yields. This resulted in the correlation declining to -0.14. According to the literature, the relationship between total yield and persistency depends essentially on the persistency measure used (Sölkner \& Fuchs, 1987). Persistency measures based on ratios are positively correlated, but measurements based on variation, negatively (Gengler, 1996). Kamidi (2005) reported a Pearson correlation coefficient of -0.39 between persistency and lactation yield, using a parametric measure for lactation persistency.

Because reliable conception dates on cows during the lactation were not available, it was not possible to accurately account for number of days open in the model. It was therefore decided to release persistency indices only for bulls, as this effect is assumed to average out over all progeny of a sire (Schaeffer et al., 2000).

In Figure 1 the relationship between some persistency indices and 60- and 280-day milk yield EBVs for Jersey bulls, is indicated. Bull A, with a persistency index of 57.3, shows a steep decline between milk yield EBVs from day 60 to day 280 in lactation, while Bull C, with a persistency index of 77.7, has an increase over the same period. Bull B, with constancy over this period, has an index of 70.4. The phenotypic averages of the base cows for the Jersey breed, $\left(\mathrm{y}_{60}=20.22 \mathrm{~kg}\right.$ and $\left.\mathrm{y}_{280}=14.28 \mathrm{~kg}\right)$, indicate that on average $70.6 \%$ of milk yield is maintained on day 280 relative to the milk yield on day 60 of lactation for cows born in 2000, which is the basis of expression of this index. All values above 70.6 therefore indicate increasing persistency and below 70.6 decreasing persistency relative to that of the base cows. This basis is of course breed specific and is 65.9, for example, for the Ayrshire breed. 


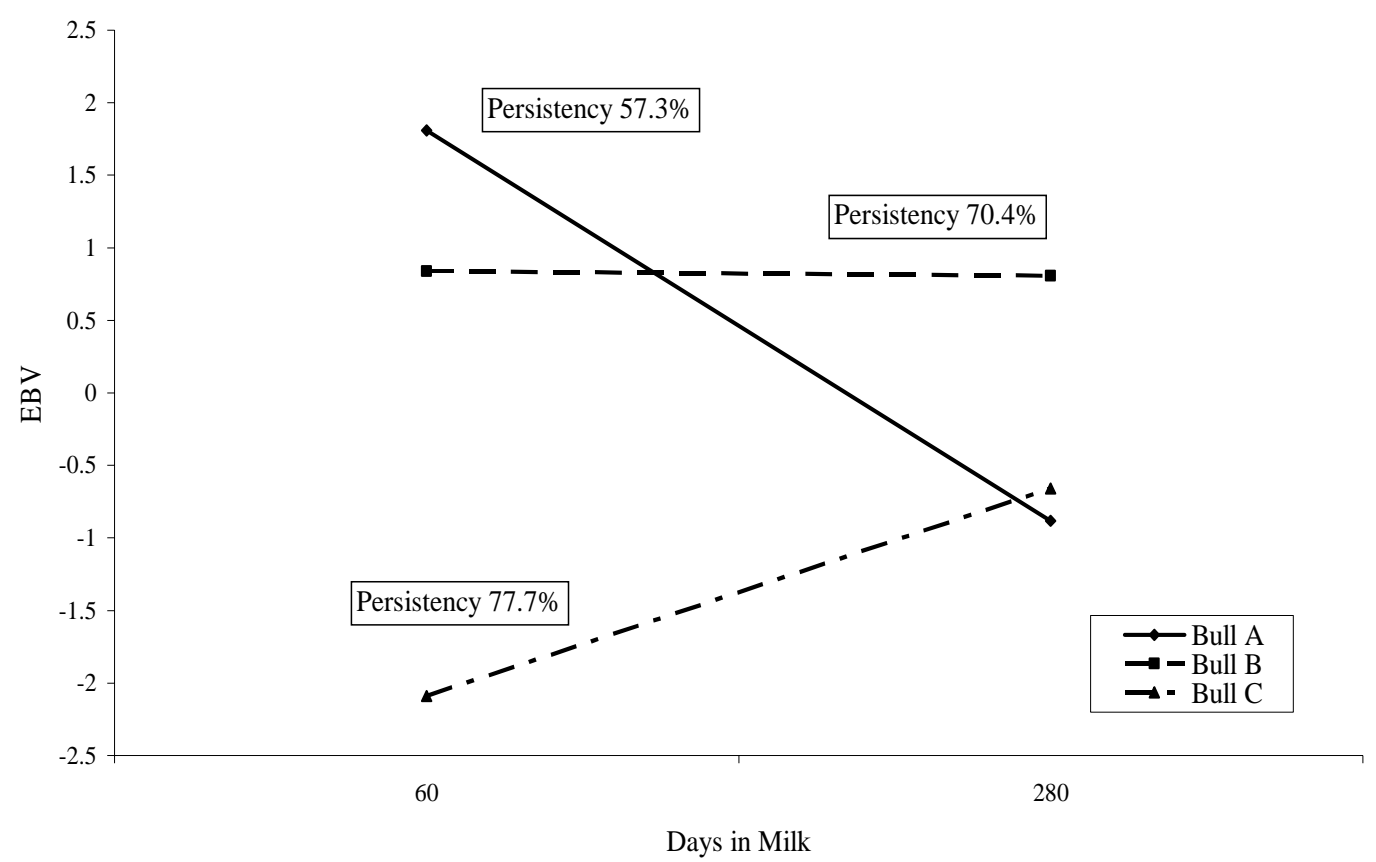

Figure 1 Relationship between persistency indices and 60- and 280-day milk yield EBVs for three Jersey bulls.

\section{Conclusions}

Procedures have been developed successfully for calculation of a Persistency Index for the South African dairy breeds. These indices will be released for sires with progeny following each national dairy genetic evaluation. The South African dairy industry will therefore be able to select for changes in persistency in future. However, according to Jamrozik et al. (1997) it is not known if selection for greater or lower persistency should be recommended to improve economic returns. Cows with high persistency may endure more stress during lactation, which could adversely affect reproduction or longevity. The ramifications of genetically changing the shape of lactation curves are not yet known and solid recommendations cannot yet be made to producers regarding selection for persistency. On the other hand, a positive genetic correlation has been found to exist between persistency and disease resistance (Dekkers et al., 1996; Jakobsen, 2000). Selection for persistency will therefore be especially useful in situations where disease resistance cannot be measured directly. The actual economical value of persistency will thus depend on local conditions and production systems used (Jensen, 2001).

\section{References}

Danell, B., 1982. Studies on lactation yield and individual test-day yields of Swedish dairy cows. II. Estimates of genetic and phenotypic parameters. Acta Agric. Scand. 32, 82-92.

Dekkers, J.C.M., Jamrozik, J., ten Hag, J.H., Schaeffer, L.R. \& Weersink, A., 1996. Genetic and economic evaluation of persistency in dairy cattle. Proc. Int. Workshop on Genetic Improvement of Functional Traits in Cattle. Gembloux, Belgium. INTERBULL Bulletin No. 12, 97-102.

Druet, T., Jaffrézic, F. \& Ducrocq, V., 2004. Estimation of genetic parameters for test day records of dairy traits in the first three lactations. Genet. Sel. Evol. 37, 257-271.

Gengler, N., 1990. Etude de la persistence des productions laitieres pendant la lactation chez la vache PieNoire. Travail de fin d'etude, Faculte Universitaire des Sciences Agronomiques de Gembloux, Gembloux, Belgium, 98.

Gengler, N., 1995. Use of mixed models to appreciate the persistency of yields during the lactation of milk cows. PhD thesis. Faculté Universitaire des Sciences Agronomiques de Gembloux, Belgium. 
Gengler, N., 1996. Persistency of lactation: a review. Proc. Int. Workshop on Genetic Improvement of Functional Traits in Cattle. Gembloux, Belgium. INTERBULL Bulletin No. 12, 87-96.

Gengler, N., Wiggans, G.R. \& Gillon, A., 2004. Estimated heterogeneity of phenotypic variance of test-day yield with a structural variance model. J. Dairy Sci. 87, 1908-1916.

Groeneveld, E. \& Garcia-Cortes, A., 1998. VCE4.0, a (co)variance component package for frequentists and bayesians. Proc. $6^{\text {th }}$ World Cong. Genet. Appl. Livest. Prod. 27, 455-456.

Groeneveld, E. \& Kovac, M., 1990. A generalized computing procedure for setting up and solving mixed linear models. J. Dairy Sci. 73, 513-531.

Jakobsen, J.H., 2000. Genetic correlations between the shape of the lactation curve and disease resistance in dairy cattle. Ph.D. thesis. Dept. of Animal Breed. Genet. Danish Institute of Agricultural Sciences, Research Centre, Foulum, Denmark.

Jamrozik, J., Janse, G., Schaeffer, L.R. \& Liu, Z., 1998. Analysis of persistency of lactation calculated from a random regression test day model. INTERBULL Bulletin No. 17, 64-69.

Jamrozik, J., Schaeffer, L.R. \& Dekkers, J.C.M., 1997. Genetic evaluation of dairy cattle using test day yields and a random regression model. J. Dairy Sci. 80, 1217-1226.

Jensen, J., 2001. Genetic evaluation of dairy cattle using test-day models. J. Dairy Sci. 84, 2803-2812.

Kamidi, R.E., 2005. A parametric measure of lactation persistency in dairy cattle. Livest. Prod. Sci. 96, 141-148.

Meyer, K., Graser, H-U. \& Hammond, K., 1989. Estimates of genetic parameters for first lactation test day production of Australian Black and White cows. Livest. Prod. Sci. 21, 177-199.

Mostert, B.E., 2007. The suitability of test-day models for genetic evaluation of dairy cattle in South Africa. $\mathrm{PhD}$ thesis. University of Pretoria, South Africa.

Mostert, B.E., Theron, H.E. \& Kanfer, F.H.J., 2001. The effect of calving season and age at calving on production traits of South African dairy cattle. S. Afr. J. Anim. Sci. 31, 205-214.

Mostert, B.E., Theron, H.E., Kanfer, F.H.J. \& Van Marle-Köster, E., 2006a. Fixed regression test-day models for South African dairy cattle for participation in international evaluations. S. Afr. J. Anim. Sci. 36, 58-70.

Mostert, B.E., Kanfer, F.H.K., Theron, H.E. \& Van Marle-Köster, E., 2006b. Adjustment for heterogeneous variances and a calving year effect in test-day models for national genetic evaluations of dairy cattle in South Africa. S. Afr. J. Anim. Sci. 36, 165-174.

NRS Handbook, 2004. Statistical Indicators. Chapter E-7. Breeding value estimation of milk production traits with test-day model. CR Delta, 1-22.

SAS, 2003. Statistical Analysis System user's guide : Statistics, Release 8.1. SAS Institute Inc., Cary, North Carolina, USA.

Schaeffer, L.R., Jamrozik, J., Kistemaker, G.J. \& Van Doormaal, B.J., 2000. Experience with a test-day model. J. Dairy Sci. 83, 1135-1144.

Sölkner, J. \& Fuchs, W., 1987. A comparison of different measures of persistency with special respect to variation of test-day milk yields. Livest. Prod. Sci. 16, 305-319.

Strabel, T., Kopacki, W. \& Szwaczkowski, T., 2001. Genetic evaluation of persistency in random regression test day models. INTERBULL Bulletin No. 27, 189-192.

Swalve, H.H., 1995. The effect of test day models on the estimation of genetic parameters and breeding values for dairy yield traits. J. Dairy Sci. 78, 929-938.

Wilmink, J.B.M., 1987. Adjustment of test-day milk, fat and protein yield for age, season and stage of lactation. Livest. Prod. Sci. 16, 335-348.

Zimmerman, E. \& Sommer, H., 1973. Zum Laktationsverlauf von Kuhen in Hochleistungsherden und dessen Beeinflussung durch nieterblicke Faktoren. Zuchtungskunde 45, 75-88. 